\title{
DUALIDADE CONSERVAÇÃO X DEGRDAÇÃO NO PATRIMÔNIO GEOMORFOLÓGICO DO MACIÇO DO GERICINÓ-MENDANHA: UMA ANÁLISE DA VERTENTE VOLTADA PARA O RIO DE JANEIRO
}

\author{
Debora Rodrigues Barbosa ${ }^{(a)}$, Natália Macedo Rodrigues ${ }^{(b)}$ \\ (a) Curso de Geografia, Universidade Estácio de Sá, debora.rodrigues.geo@gmail.com \\ (b) Curso de Geografia, Universidade Estácio de Sá, natalia.geo.rodrigues@ gmail.com
}

\section{Eixo: GEODIVERSIDADE, GEORARQEOLOGIA E PATRIMÔNIO NATURAL}

\begin{abstract}
Resumo
As áreas naturais, sofrem, de uma maneira geral, com todo o processo de crescimento urbano. Nelas, ocorrem práticas de desmatamento, que estão ligada ao crescimento imobiliário ilegal e desenfreado, que assola cada vez mais as grandes capitais brasileiras. Na cidade do Rio de Janeiro, a Mata Atlântica tem sido degradada para dar lugar à expansão do tecido urbano, que precisa do desmatamento, como forma de apropriação do território. Nesse sentido, o governo estadual tem buscado a criação e organização de espaço protegidos a partir da Lei Federal instituiu o Sistema Nacional de Unidades de Conservação da Natureza (SNUC), estabelecendo critérios e normas para a criação, implantação e gestão das unidades de conservação. Assim, nesse trabalho, será apresentada a dualidade conservação x degradação no entono do Maciço do Gericinó-Mendanha, no trecho voltado para a Zona Oeste do Rio de Janeiro.
\end{abstract}

Palavras chave: Gestão Ambiental, Unidades de Conservação, Maciço do Gericinó-Mendanha, Rio de Janeiro.

\section{Introdução}

A Região Metropolitana do Rio de Janeiro tem sofrido forte crescimento populacional a partir da segunda metade do século passado, quando as políticas públicas orientaram a transformação espaço-industrial da Região Sudeste brasileira e grandes obras permearam a metrópole e vizinhança.

A cidade do Rio de Janeiro cresceu em torno do seu centro histórico, gerando grande especulação no valor de propriedade dessa área, forçando a população de menor poder aquisitivo a buscar glebas mais baratas, muitas vezes, situadas em encostas e fundos de vales fluviais.

Para proteger os recortes verdes, o Governo Federal, através da Lei Federal 9.985, de 18 de julho de 2000, instituiu o Sistema Nacional de Unidades de Conservação da Natureza (SNUC), estabelecendo critérios e normas para a criação, implantação e gestão das unidades de conservação.

No Estado do Rio de Janeiro, o INEA administra um amplo conjunto de unidades de conservação da natureza (UCs), que protegem amostras representativas de todos os ecossistemas nativos associados à 
Mata Atlântica fluminense, garantindo refúgio para inúmeras espécies de plantas e animais vulneráveis ou ameaçados de extinção.

Dentro desse contexto, é fundamental analisar a dualidade conservação e degradação das Unidades de Conservação presentes nas vertentes voltadas para o Rio de Janeiro do Maciço do Gericinó-Mendanha, portanto esse trabalho tem o objetivo de analisar o processo de ocupação no entorno do Maciço.

\section{Materiais e Métodos}

Esse trabalho contou com diferentes etapas metodológicas, dentre elas a revisão bibliográfica das bases legais de implantação das diferentes unidades de conservação que protegem o Maciço do GericinóMendanha.

Em um segundo momento, recorreu-se a uma pesquisa bibliográfica sobre a área estudada, o maciço do Gericinó-Mendanha. Foram realizadas pesquisas a respeito da estrutura física do maciço, como características de sua geologia, pedologia, fauna e flora. A seguir, foram realizadas pesquisas sobre o processo de ocupação dessa área, a partir de artigos científicos.

A terceira etapa do presente trabalho consistiu no trabalho de campo, realizado no dia 27 de setembro de 2014, ao Parque Estadual do Mendanha com o intuito de obtenção de dados mais específicos sobre a Unidade de Conservação presente nesta porção do maciço. Foram obtidos dados do Parque, a partir de informações passadas pelo gestor da UC, o geógrafo Dario Moreira, que coordenou o trabalho de campo. Foram obtidas fotos da Unidade de Conservação, desde seu ponto de entrada, a fim de verificar irregularidades, como construções desordenadas e lançamento de esgoto nos córregos, despejo inadequado de lixo e práticas agrícolas, até uma das áreas mais altas, onde ficam localizadas cachoeiras muito visitadas pela população local.

\section{Resultados e Discussões}

O maciço de Gericinó-Mendanha é um dos três grupos de maciços costeiros localizados no Município do Rio de Janeiro. A unidade geomorfológica é conhecida por possuir características a própria Mata atlântica original, abrigando espécies ameaçadas de extinção e o vulcão extinto da era cenozoica período terciário. Abrange uma área que compreende as serras de Madureira, Marapicu, Gericinó e Mendanha, localizadas na região metropolitana do Estado do Rio de Janeiro, abrangendo os municípios do Rio de Janeiro, Nilópolis Mesquita e Nova Iguaçu.

O maciço do Gericinó-Mendanha ocupa uma área de aproximadamente $105 \mathrm{~km}^{2}$, onde sua encosta sul está voltada para a Zona Oeste da capital, entre os bairros de Campo Grande e Bangu e as encostas leste e norte, para os municípios de Nilópolis, Mesquita, Nova Iguaçu e parte do Rio de Janeiro. 
A região passou a ser conhecida pelos primeiros colonizadores a partir de 1603, no início do século XVII, quando cultivaram canaviais, abrindo caminhos de acessos, e construíram seus engenhos de açúcar que eram o motor da economia da época, provavelmente ocupando as baixadas circundantes (OESTE CARIOCA, 2014).

A cafeicultura foi praticada até o século XIX, onde no final deste, o processo de urbanização começou a se configurar na região. Tal processo teve seu ápice com a construção do ramal Santa Cruz da Estrada de Ferro Central do Brasil, chegando até Bangu. Outro fator importante para o processo de urbanização da área foi a construção da Companhia Progresso Industrial, conhecida como Fábrica Bangu, em 1893. A principal época de ocupação da Zona Oeste deu-se com a abertura da Estrada Rio São Paulo, em 1930 e com a construção da Avenida Brasil, em 1946.

Atualmente, com o processo de ocupação irregular, algumas das áreas com vegetação original deram lugar a áreas de pastagem e cultivo, principalmente àquele chamado de desmatamento verde (Gama et. al., 2006), onde a vegetação é retirada para dar lugar a cultivos, geralmente de bananeiras.

Destaca-se, no entanto, que o maciço apresenta $60 \%$ das florestas em ótimo estado de conservação, enquanto os $40 \%$ restante são constituídos por vegetações secundárias (Barbosa, Silva e Souza, 2015). As áreas mais preservadas encontram-se nas cotas altimétricas mais elevadas, onde podem ser vistas em estado primitivo ou até mesmo clímax. Nesse sentido, o maciço pode ser considerado região prioritária para a preservação da biodiversidade e mananciais hídricos.

Essa região abriga um dos últimos grandes remanescentes florestais da região metropolitana do Rio de Janeiro, tendo sido declarada como Reserva da Biosfera pela Organização das Nações Unidas para a Educação, a Ciência e a Cultura (UNESCO) em 1992 (Spolidoro, 1998).

A preocupação em preservar o maciço do Gericinó-Mendanha data da década de 1940, quando a partir do Decreto-Lei número 3.889, de 5 de dezembro de 1941, houve a transferência das atividades de proteção e guarda das florestas da União o Serviço Florestal do Ministério da Agricultura, transformando a área do maciço em Floresta Protetora da União. Um fator de proteção é a presença de duas das escolas de instrução das Forças Armadas: Campo de Instrução do Gericinó (CIG) e o Centro de Instrução Almirante Milcíades Portela Alves (CIAMPA).

Atualmente, há também, diferentes unidades de conservação, como é o caso do Parque Estadual do Mendanha, a Área de Proteção Ambiental Estadual do Gericinó-Mendanha, o Parque Natural Municipal da Serra do Mendanha, o Parque Natural Municipal de Nova Iguaçu e Parque Natural Municipal de Mesquita. 
As Unidades de Conservação consistem em áreas legalmente instituídas pelo poder público nas suas três esferas e estão divididas em dois grupos: as Unidades de Conservação de Proteção Integral e as Unidades de Conservação de Uso Sustentável.

Como o trabalho refere-se à vertente voltada para a Zona Oeste do Rio de Janeiro, é fundamental apresentar as duas unidades de conservação da área (Tabela 01).

Tabela 1 - Unidades De Conservação Do Maciço Gericinó-Mendanha - Zona Oeste Do Rio De Janeiro

\begin{tabular}{|c|c|c|c|}
\hline $\begin{array}{c}\text { Unidade de } \\
\text { Conservação }\end{array}$ & Lei/Decreto & Área & Abrangência/ Municípios \\
\hline $\begin{array}{c}\text { Área de Proteção } \\
\text { Ambiental Gericinó- } \\
\text { Mendanha }\end{array}$ & $\begin{array}{c}\text { Lei Estadual 1.331, de } \\
12 \text { de julho de 1988 }\end{array}$ & 7.972 hectares & $\begin{array}{c}\text { Território ocupado pelas serras de } \\
\text { Madureira, Marapicu, Gericinó e } \\
\text { Mendanha Nova Iguaçu, Mesquita e Rio } \\
\text { de Janeiro }\end{array}$ \\
\hline $\begin{array}{c}\text { Parque Natural da Serra } \\
\text { do Mendanha }\end{array}$ & $\begin{array}{c}\text { Lei Municipal n } 1.958, \\
\text { de } 5 \text { de abril de } 1993\end{array}$ & 1.500 hectares & $\begin{array}{c}\text { Bairros de Bangu e Campo Grande, no } \\
\text { Rio de Janeiro }\end{array}$ \\
\hline $\begin{array}{c}\text { Parque Estadual do } \\
\text { Mendanha }\end{array}$ & $\begin{array}{c}\text { Decreto Estadual } \mathrm{n}^{\circ} \\
44.342, \text { de } 22 \text { de agosto } \\
\text { de } 2013\end{array}$ & $4.398,10$ hectares & $\begin{array}{c}\text { Partes dos municípios do Rio de Janeiro, } \\
\text { Nova Iguaçu e Mesquita }\end{array}$ \\
\hline
\end{tabular}

A exceção do Parque Estadual, essas Unidades de Conservação vêm sofrendo, ao longo dos anos, com a presença de população e diversas ações antrópicas. Gama (2002) define essa população em três classes: vizinhos, moradores e visitantes eventuais. Os "vizinhos" consistem na população que habita o entorno imediato, limitado pela Avenida Brasil. Os "moradores" são aqueles que habitam residências precárias, já previamente estabelecidas, geralmente herdadas ou invadidas e são, em maioria, dependentes da atividade agrícola. E os "visitantes eventuais" caracterizam-se pela população residente em municípios vizinhos que vão até a região em busca de práticas de lazer. Há ainda o que Gama chama de "visitantes trilheiros", que são aqueles que frequentam a região de forma mais assídua, geralmente aos finais de semana.

De uma forma ou de outra, essas populações acabam por impactar a região de estudo, uma vez que a mesma sofre com problemas como falta de saneamento básico, tendo esgoto lançado a céu aberto, falta de água encanada, carência de destinação adequada ao lixo, sendo caracterizados como "usos indevidos" (Gama op. cit.). Além desses usos, há também pressão antrópica oriunda das grandes vias expressas que circundam a região, como a Avenida Brasil, com também das de menor impacto, como a Estrada Guandu do Sena, Estrada do Mendanha, acabando por colaborar no processo de fragmentação do referido ecossistema.

Outro problema importante que precisa de solução urgente, associado às ocupações irregulares, diz respeito ao lançamento de esgoto e de lixo diretamente nos cursos d'água, sem nenhum tipo de tratamento. 


\section{Considerações Finais}

Mesmo com todos os problemas no interior e no entorno do Parque, é perceptível que sua presença é de extrema importância, não só para garantir o equilíbrio ecológico, mas também atrair cada vez mais a atenção da população e de profissionais das ciências ditas ambientais e visitarem e se preocuparem com a preservação do bioma e analisar a dualidade presente na região do maciço, que consiste na degradação convivendo com a conservação ainda presente.

Se por um lado existe a ocupação irregular, o lançamento de esgoto, a poluição e degradação do ambiente natural, por outro existe uma legislação vigente e que protege o bioma mata atlântica, conseguindo manter $60 \%$ dessa vegetação nativa na região e $40 \%$ de vegetação secundária.

Nesse sentido, é possível identificar a conservação e a degradação convivendo no mesmo ambiente, que mesmo com todas as mazelas da pressão e ocupação antrópica, ainda consegue ser berço de um grande patrimônio de biodiversidade, a Mata Atlântica nativa e sua fauna endêmica.

\section{REFERÊNCIAS}

BARBOSA, D.R; SILVA, B. B. C.; SOUZA, G. S. BACIA HIDROGRÁFICA COMO UNIDADE DE PLANEJAMENTO: O ESTUDO DA BACIA DO RIO GUANDU DO SAPE (RIO DE JANEIRO). In: SIMPOSIO BRASILEIRO DE GEOGRAFIA FÍSICA APLICADA, 15, 2015, Teresina. Anais... Teresina: Universidade Federal do Piaui, 2015.

GAMA, S. V. G. da. Contribuição metodológica à gestão ambiental integrada de Unidades de Conservação - O Caso do Maciço Gericinó-Mendanha - Zona Oeste do Município do Rio de Janeiro. 2002. 198 f. Tese (Doutorado em Geografia) - Instituto de Geociências, Universidade Federal do Rio de Janeiro, Rio de Janeiro.

OESTE CARIOCA - GRUPO DE ESTUDOS SOCIOAMBIENTAIS. O que é e onde é o Maciço do GericinóMendanha? Disponível em <http://oestecarioca-estudos.blogspot.com.br/2014/11/o-que-e-e-onde-e-o-macico-dogericino.html>. Acesso em 02 nov. 2014.

SPOLIDORO, M. L. C. V. Fatores ambientais que afetam a distribuição e frequência de capinzais na Serra de Madureira - Mendanha, RJ. 1998. 45 f. Monografia (Curso de Especialização em Ciências Ambientais). Universidade Federal Rural do Rio de Janeiro, Seropédica. 